\title{
Experimental Comparison of the Low-Frequency Noise of Small-Size Magnetic Sensors
}

\author{
Jan Vyhnanek and Pavel Ripka \\ Department of Measurement, Faculty of Electrical Engineering, Czech Technical \\ University in Prague, 16627 Prague, Czech Republic
}

Small-size ac magnetic-field sensors are used for nondestructive testing (NDT), magnetic particle detection, and other applications, which require high spatial resolution. Up to now, inductive coils dominated this area, as their sensitivity at $\mathrm{kHz}$ frequencies, are superior to other magnetic sensors. However, some applications, such as magnetic imaging through conducting sheath, require lower working frequencies, in extreme case units of Hz. We successfully replaced inductive coils by an AMR sensor in NDT application and for distance measurement. In this paper, we compare designs of miniature ac magnetic field sensors, their achievable frequency characteristics, dynamic range, and noise parameters.

Index Terms-Magnetic sensors, noise measurement.

\section{INTRODUCTION}

$\mathrm{C}$ OMPARISON of magnetic sensors of different technologies was recently done by Robbes in [1]. He used energy resolution-volume criterion and concluded that SQUID and SERF achieve the best resolution. However, these sensors are not practical for the industrial applications such as nondestructive testing (NDT).

In this paper, we compare commonly available small-size room temperature sensors: an induction coil with $8 \mathrm{~mm}$ long ferrite core (Fig. 1) and commercial fluxgate and AMR sensors. The selected sensors have comparable dimensions of the casing rather than the sensing element size. This is a practical criterion for the design of gradiometers or multiple sensor detectors. Dimensions of the sensing element, however, influence the spatial resolution of the sensor, an important requirement, e.g., in NDT applications, in position sensing, and in the detection of small ferromagnetic or superparamagnetic objects. Gruger [2] describes an array of planar fluxgate sensors for NDT. The sensors are $1 \mathrm{~mm}$ long and they have $0.5 \mathrm{~mm}$ pitch. Vertesy and Gasparics [3] used a similar sensor with time-output and unipolar excitation. Butin et al. [4] and Dolabdjian et al. [5] replaced induction coil in a pulsed eddy current system by GMR sensors. We have used an AMR sensor instead of the induction coil in the eddy-current position and distance sensor [6].

In this paper, we compare sensor noise at low frequencies, i.e., DC to $1 \mathrm{kHz}$ following the study we made on AMR sensors [7]. In this frequency range, the sensor noise is the limiting factor for NDT applications. Similar study of magnetoresistive sensors was made by Stutzke et al. [8].

\section{INDUCTION COIL}

Induction coils are traditionally used in geophysics to measure magnetic field variations [9]. An induction coil can reach

Manuscript received August 10, 2016; revised November 15, 2016; accepted November 19, 2016. Corresponding author: J. Vyhnanek (e-mail: vyhnajan@ fel.cvut.cz).

Color versions of one or more of the figures in this paper are available online at http://ieeexplore.ieee.org.

Digital Object Identifier 10.1109/TMAG.2016.2633398

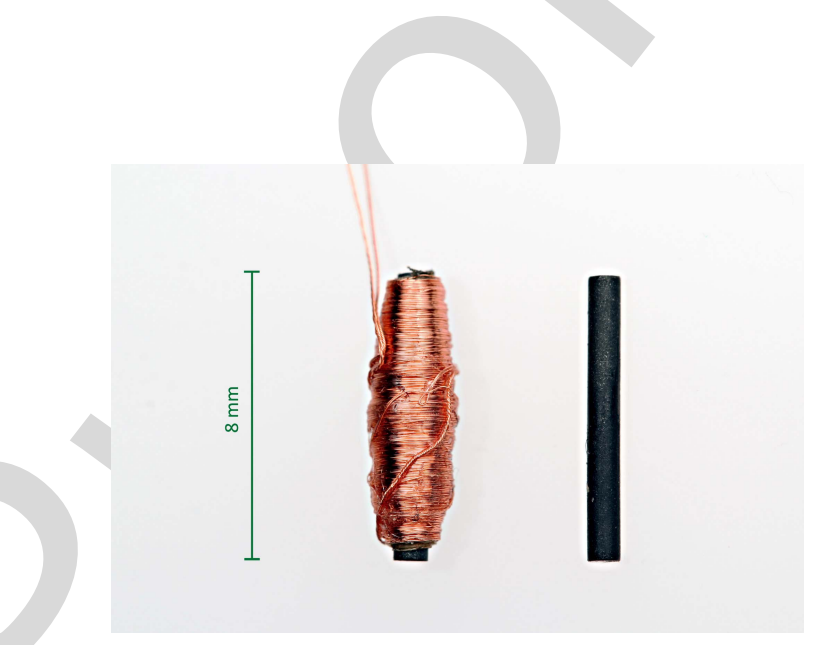

Fig. 1. Sensor with 2000 turns wound around a ferrite core and a ferrite core without the winding.

a resolution of fluxgate sensors at $1 \mathrm{~Hz}$, but the dimensions and weight of such a coil is usually large [10], [11].

In the position detectors with moving magnets, induction sensors have been replaced by Hall and AMR sensors, which have speed-independent signal. However, induction coils are the most popular sensors in eddy current position sensors and NDT systems. Induction coils can be used either in the voltage output mode or in the current output mode. Theoretical model and real data comparison of a coil with the same instrumentation amplifier INA163, which was used here, are given in [12].

An induction coil with 2000 turns and $8 \mathrm{~mm} \times 1 \mathrm{~mm}$ ferrite core was developed in our laboratory and successfully tested in vivo as an inductive distance sensor to monitor gastric motility [13]. The coil is wound with a $0.035 \mathrm{~mm}$ diameter copper wire and its resistance $R_{S}$ is $200 \Omega$.

After inserting the ferrite core, the coil inductance $L_{S}$ was increased by the factor of 13 (from 1.4 to $18.6 \mathrm{mH}$ ) and the sensitivity increased by the factor of 12 at all frequencies. These are lower values than the theoretical apparent permeability of 50 according to [14]. One explanation of this discrepancy may be the influence of the real coil geometry.

The frequency dependence of the sensitivity of voltage output coil is shown in Fig. 2(a). The resonance peak of the 

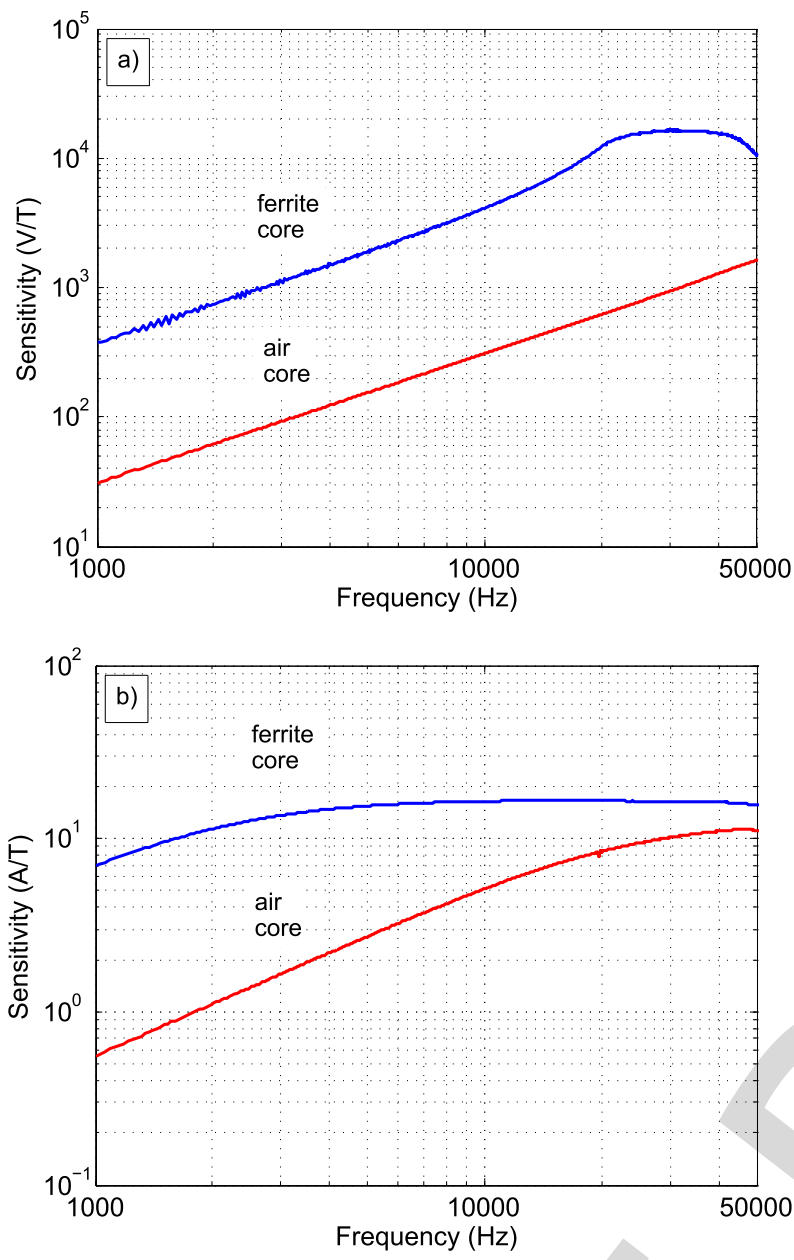

Fig. 2. Frequency dependence of the $8 \mathrm{~mm}$ long induction coil with and without ferrite core (a) with voltage output and (b) with current output. cored coil is caused by coil self-capacitance in parallel with inductance.

The theoretical disadvantage of the induction coil with voltage output is its strong frequency dependence of sensitivity. The coil with current output is theoretically frequency independent for frequencies higher than

$$
f_{c}=R_{s} /\left(2 \pi L_{s}\right) .
$$

However, for small induction coils, this frequency is very high. The real frequency characteristics of the current output coil with and without a core are shown in Fig. 2(b). For the cored coil and the current output, the measured cutoff frequency corresponds to the theoretical value $f_{c}=1.7 \mathrm{kHz}$ for $L_{s}=$ $18.6 \mathrm{mH}$. For the air coil, the calculated $f_{c}$ is $23 \mathrm{kHz}$.

Fig. 3 compares three conditioning circuits connected to the cored induction coil to select the optimal method of signal processing. Transimpedance amplifiers with INA163 and LT1028 were used for the current output. The value of the conversion resistor is $6 \mathrm{k} \Omega$. The coil in the voltage output mode was connected to a voltage amplifier with INA163 with the gain of 1000 . From the measured characteristics, we may conclude that for this type of the induction coil, voltage amplification is the best to achieve minimum noise.

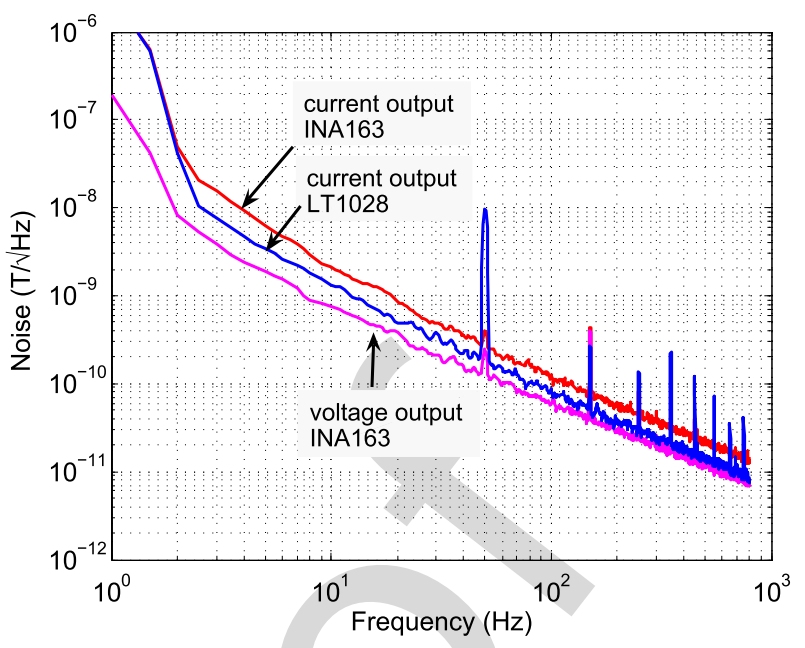

Fig. 3. Comparison of induction coil noise with voltage amplifier and transimpedance amplifier (current output) for $1-800 \mathrm{~Hz}$.
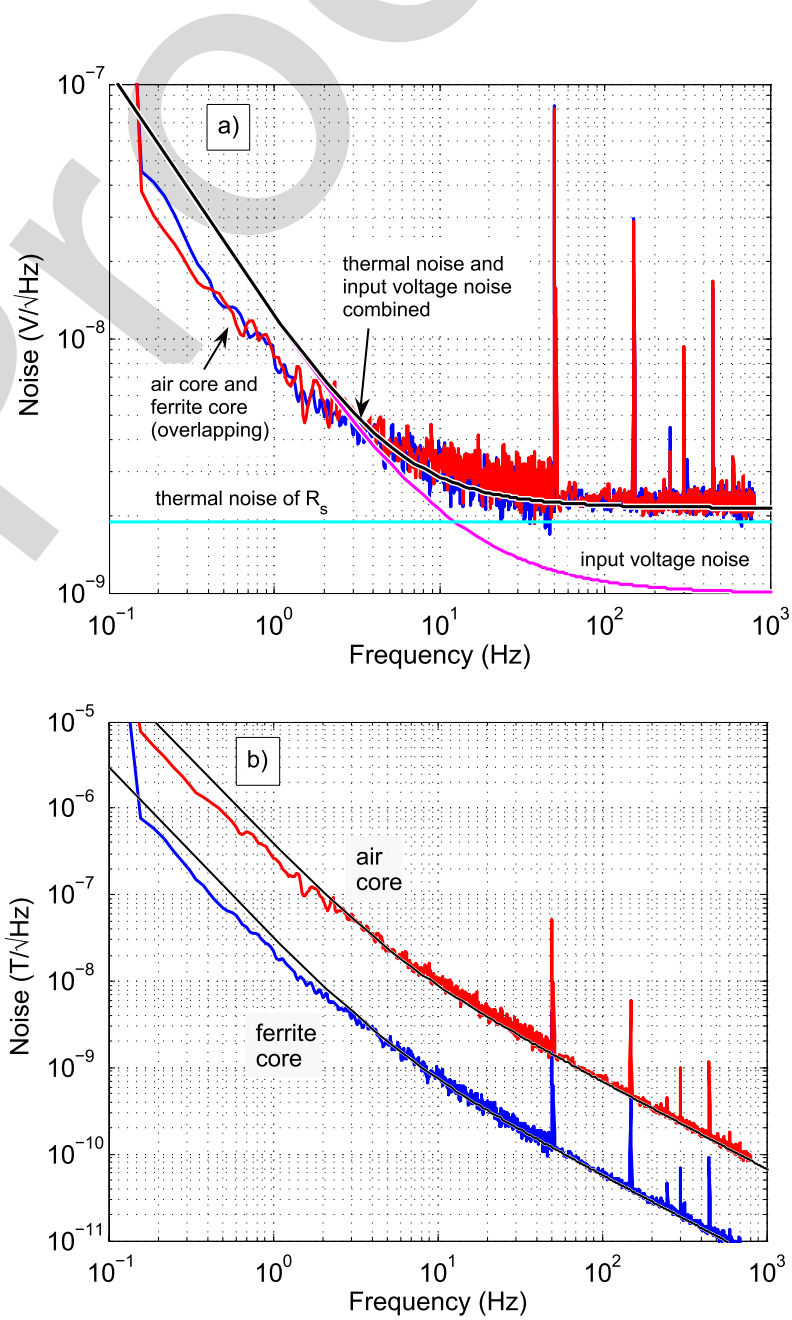

Fig. 4. Induction coil with core connected to INA163 voltage amplifier compared with modeled thermal noise and voltage noise of INA163. (a) In volts. (b) Recalculated in the units of magnetic field.

Fig. 4(a) shows the measured and modeled noise voltage for the voltage output coil compared with the calculated values. For the frequencies below $10 \mathrm{~Hz}$, the dominant source of the noise is $1 / f$ voltage noise of the amplifier, while the 
TABLE I

COMPARISON SUMMARY

\begin{tabular}{|c|c|c|c|c|c|c|c|}
\hline Sensor & Conditioning circuit & $\begin{array}{c}\text { Sensor } \\
\text { dimensions }\left(\mathrm{mm}^{3}\right)\end{array}$ & $\begin{array}{c}\text { Sensor } \\
\text { weight }(\mathrm{g})\end{array}$ & $\begin{array}{l}\text { Freq. upper } \\
\text { limit }(\mathrm{kHz})\end{array}$ & $\begin{array}{c}\text { Sensor } \\
\text { range }(\mathrm{mT})\end{array}$ & $\begin{array}{l}\text { Noise, } 10 \mathrm{~Hz} \\
(\mathrm{nT} / \sqrt{\mathrm{Hz}})\end{array}$ & $\begin{array}{l}\text { Noise, } 100 \mathrm{~Hz} \\
(\mathrm{nT} / \sqrt{\mathrm{Hz}})\end{array}$ \\
\hline Coil, air core & INA163, G=1000x & $8 \times 2.5 \times 2.5$ & 0.01 & $>50$ & $>1000$ & 10 & 0.8 \\
\hline Coil, ferrite c. & INA163, $G=1000 \times$ & $8 \times 2.5 \times 2.5$ & 0.13 & 20 & 5 & 0.8 & 0.07 \\
\hline Coil, fluxgate & Lock-in SR865 & $8 \times 2.5 \times 2.5$ & 0.13 & 1 & $<5$ & 1.2 & 1 \\
\hline HMC1001 & $\mathrm{AD} 8429, \mathrm{G}=100 \times$ & $11 \times 4 \times 2$ & 0.15 & $4 *$ & 0.2 & 0.065 & 0.05 \\
\hline HMC2003 & included in sensor & $27 \times 20 \times 9$ & 1.28 & 1 & 0.2 & 0.25 & 0.25 \\
\hline DRV425 & included in sensor & $4 \times 4 \times 0.8$ & 0.04 & 32 & 2 & 1.5 & 1 \\
\hline
\end{tabular}

*4 kHz with $10 \mathrm{kHz}$ flipping and demodulation, $1.2 \mathrm{MHz}$ without flipping

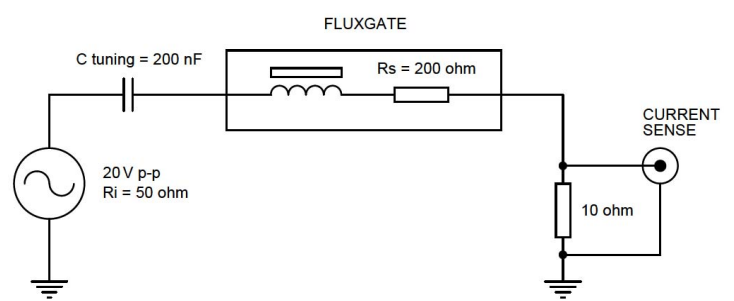

Fig. 5. Setup for the fluxgate sensor with current output.

contribution from the current noise is negligible. The noise model is based on datasheet data. The theoretical white noise of the coil is mainly determined by the thermal noise voltage of the coil resistance and the white noise region $U_{n}$ of the voltage noise of the amplifier; for $R_{s}=200 \Omega, U_{n}=1 \mathrm{nV} / \sqrt{\mathrm{Hz}}$, room temperature $T$, and Boltzmann constant $k$, the combined white noise results in

$$
U_{\text {white_total }}=\sqrt{4 k T R_{S}+U_{n}^{2}}=2.1 \mathrm{nV} / \sqrt{\mathrm{Hz}} .
$$

The measured value is $2.3 \mathrm{nV} / \sqrt{\mathrm{Hz}}$. As the measured voltage noise with and without core is identical, the contribution of the magnetic noise of the core is negligible. Noise recalculated to the field units is shown in Fig. 4(b). It is clear that due to the frequency dependence of the sensitivity, the noise decreases with frequency monotonically. The achieved noise level with the cored coil is $0.8 \mathrm{nT} / \sqrt{\mathrm{Hz}} @ 10 \mathrm{~Hz}$ and $22 \mathrm{nT} / \sqrt{\mathrm{Hz}} @ 1 \mathrm{~Hz}$.

The cored induction coil has a field amplitude range limited by the saturation of the core to $5 \mathrm{mT}$. Compared with that, the upper field range of the air coil is only limited by the output amplifier. In our case, the maximum measurable field on the high-resolution range is $1 \mathrm{mT}$. This field range can be further extended even over $1 \mathrm{~T}$ by decreasing the amplifier gain.

We also tested signal processing by analog integrator: homemade using LT1028 and commercially available Lakeshore 480. Due to the high resistance of the induction coil, the value of feedback capacitor should be about $1 \mu \mathrm{F}$ and resulting sensitivity is very low.

\section{Induction CoIL AS A Single Rod FluXgate}

The described miniature induction coil can be turned into the fluxgate sensor. The advantage of this unusual sensor is that it has only one winding. Setup for the fluxgate mode measurement is shown in Fig. 5. The sensor is excited in the voltage mode using $20 \mathrm{~V}_{\mathrm{p}-\mathrm{p}} / 2.3 \mathrm{kHz}$ sinusoidal voltage. The capacitor $\mathrm{C}$ serves to decouple any dc component in the

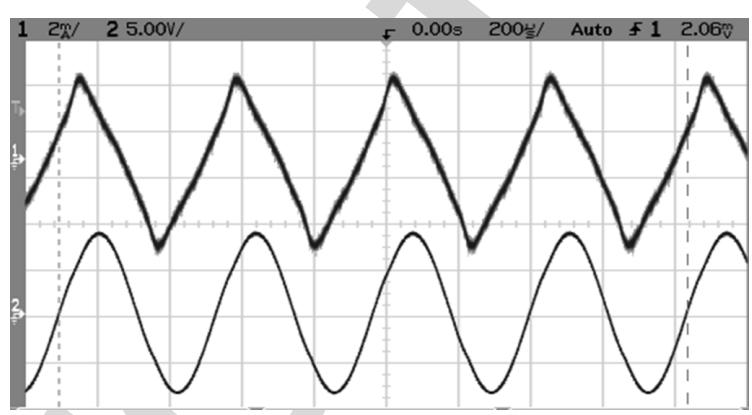

Fig. 6. Sensor current with higher harmonics due to core saturation (upper trace, $2 \mathrm{~mA} / \mathrm{div}$ ) and generator voltage (lower trace, $5 \mathrm{~V} / \mathrm{div}$ ).

excitation and to increase the excitation current amplitude by tuning.

The generator voltage and the corresponding sensor current are shown in Fig. 6. The excitation current was $8 \mathrm{~mA}_{\mathrm{p}-\mathrm{p}}$. When the external dc field is present, second-harmonic component appears in the excitation current. This second harmonics is measured as a voltage drop across the $10 \Omega$ sensing resistor by the SR865 lock-in amplifier. At higher frequencies, most of the noise in the setup comes from the amplifier in this case considering the large feedthrough of the excitation signal to the output current.

Sensitivity dependence on the frequency of the excitation current was measured for constant excitation voltage of $20 \mathrm{~V}_{\mathrm{p}-\mathrm{p}}$ (Fig. 7), and for the noise measurement, an excitation frequency of $2.3 \mathrm{kHz}$ in the high-sensitivity region was selected.

Comparing the noise of fluxgate mode and induction mode (Fig. 8), a crossing of the two characteristics at around $10 \mathrm{~Hz}$ indicates the suitability of each mode for a specified frequency region: for frequencies from $\mathrm{DC}$ to $10 \mathrm{~Hz}$, the recommended sensor mode is fluxgate, for higher frequencies induction coil.

\section{Comparison With Commercial Sensors}

We compared the performance of the developed sensors with sensors available on the market. The results are shown in Fig. 9 and a summary of parameters is given in Table I.

HMC2003 is a three-axis magnetic sensor module manufactured by Honeywell, which contains AMR sensor HCM1001 with instrumentation amplifier and a biasing source. The measured noise at $10 \mathrm{~Hz}$ is $250 \mathrm{pT} / \sqrt{\mathrm{Hz}}$. No flipping 


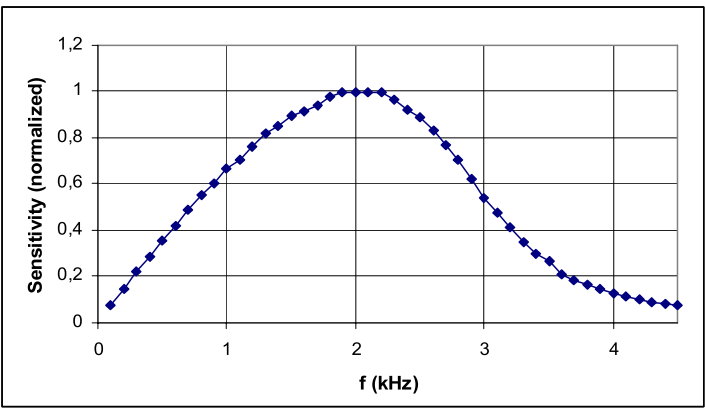

Fig. 7. Sensitivity of the fluxgate sensor in the measurement setup at the variable excitation frequency.

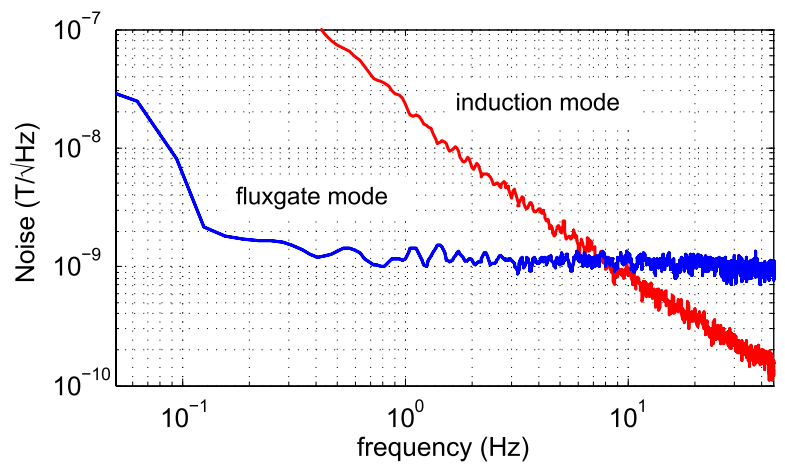

Fig. 8. Coil in fluxgate mode compared with induction mode using voltage output.

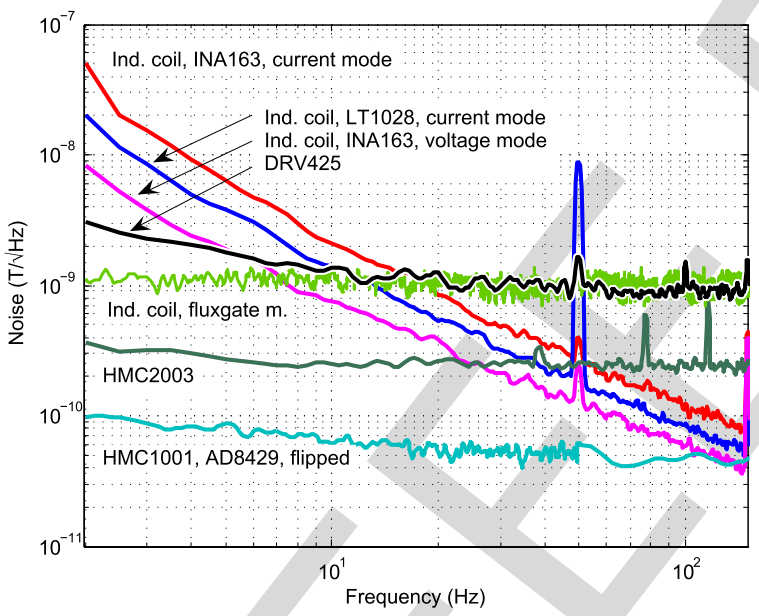

Fig. 9. Comparison of induction coil with AMR and fluxgate sensors for $2-250 \mathrm{~Hz}$.

(set/reset of the magnetic state) was applied. However, for practical applications, the sensor should be periodically remagnetized ("flipped") to ensure zero stability.

The same AMR sensor HMC1001 was characterized with enhanced electronics in [7]. The sensor was flipped at $10 \mathrm{kHz}$ with an amplitude of 3.6 $\mathrm{A}_{\mathrm{p}-\mathrm{p}}$ and connected to a low-noise instrumentation amplifier AD8429 with a gain of 100. The biasing voltage was $5.5 \mathrm{~V}$. After synchronous demodulation, the noise at $10 \mathrm{~Hz}$ is $65 \mathrm{pT} / \sqrt{\mathrm{Hz}}$.

A serious limitation of the AMR sensors is their limited dynamic range. In this case, the maximum measurable field is $0.2 \mathrm{mT}$.

The last sensor in this comparison is integrated fluxgate DRV425 manufactured by Texas Instruments. This device has both microfabricated fluxgate and complete electronics on a single CMOS-chip. We have used it in recommended circuit connection and $5.1 \mathrm{ohm}$ shunt resistor to measure feedback current [15]. The measured noise is $1.5 \mathrm{nT} / \sqrt{\mathrm{Hz}} @ 10 \mathrm{~Hz}$. The maximum field range is $2 \mathrm{mT}$, which is 10 times the range of the AMR sensor.

\section{CONCLUSION}

In this paper, we compared the noise performance of smallsize magnetic sensors suitable for NDT testing. With the exception of DRV425, the tested sensors work in open-loop. We describe small-size induction coil with high field range and noise level of $0.8 \mathrm{nT} / \sqrt{\mathrm{Hz}} @ 10 \mathrm{~Hz}$. At lower frequencies, the fluxgate mode of the same sensor is preferable, which at $1 \mathrm{~Hz}$ achieves already about 20 times better noise. Many industrial applications require high field range. From this point, the integrated fluxgate DRV425 offers the range of $2 \mathrm{mT}$, which is 10 times higher than that of AMR sensors. Our induction sensor works up to $5 \mathrm{mT}$ with core and $>1 \mathrm{~T}$ without the core.

\section{REFERENCES}

[1] D. Robbes, "Highly sensitive magnetometers-A review," Sens. Actuators A, Phys., vol. 129, no. 1, pp. 86-93, 2006.

[2] H. Grüger, "Array of miniaturized fluxgate sensors for non-destructive testing applications," Sens. Actuators A, Phys., vol. 106, no. 1, pp. 326-328, 2003.

[3] G. Vértesy and A. Gasparics, "Nondestructive material evaluation by novel electromagnetic methods," Mater. Sci. Forum, vol. 414, pp. 343-352, 2003.

[4] L. Butin, G. Waché, L. Perez, and C. Dolabdjian, "New NDE perspectives with magnetoresistance array technologies-From research to industrial applications," Insight, Non-Destructive Test. Condition Monitor., vol. 47, no. 5, pp. 280-284, 2005.

[5] C. P. Dolabdjian, L. Perez, V. O. De Haan, and P. A. De Jong, "Performance of magnetic pulsed-eddy-current system using high dynamic and high linearity improved giant magnetoresistance magnetometer," IEEE Sensors J., vol. 6, no. 6, pp. 1511-1517, Jun. 2006.

[6] P. Ripka, J. Vyhnanek, M. Janosek, and J. Vcelak, "AMR proximity sensor with inherent demodulation," IEEE Sensors J., vol. 14, no. 9, pp. 3119-3123, Sep. 2014

[7] J. Vyhnanek, M. Janosek, and P. Ripka, "Low frequency noise of anisotropic magnetoresistors in DC and AC-excited metal detectors," J. Phys. Conf. Ser, vol. 450, no. 1, p. 012031, 2013.

[8] N. A. Stutzke, S. E. Russek, D. P. Pappas, and M. Tondra, "Low-frequency noise measurements on commercial magnetoresistive magnetic field sensors," J. Appl. Phys., vol. 97, no. 10, pp. 10Q107-1-10Q107-3, 2005.

[9] S. Tumanski, "Induction coil sensors-A review," Meas. Sci. Technol., vol. 18, no. 3, pp. R31-R46, 2007.

[10] A. Roux et al., "The search coil magnetometer for THEMIS," Space Sci. Rev., vol. 141, pp. 265-275, 2008.

[11] E. Paperno and A. Grosz, "A miniature and ultralow power search coi optimized for a $20 \mathrm{mHz}$ to $2 \mathrm{kHz}$ frequency range," J. Appl. Phys., vol. 105 , no. 7 , p. 07E708, 2009

[12] M. Timofeeva, G. Allegre, D. Robbes, and S. Flament, "Differential search coils based magnetometers: Conditioning, magnetic sensitivity, spatial resolution," Sensors Transducers J., vol. 14, no. 1, pp. 134-150, 2012.

[13] J. Tomek, "Inductive contactless distance measurement intended for a gastric electrical implant," Acta Polytech., vol. 47, nos. 4-5, pp. 76-79, 2007.

[14] P. Ripka, "Induction sensors," in Magnetic Sensors and Magnetometers, P. Ripka ed. Norwood, MA, USA: Artech House, 2001.

[15] M. F. Snoeij, V. Schaffer, S. Udayashankar, and V. M. Ivanov, "An integrated fluxgate magnetometer for use in closed-loop/open-loop isolated current sensing," IEEE J. Solid-State Circuits, vol. 51, pp. 1684-1694, 2016. 


\section{AUTHOR QUERIES}

\section{AUTHOR PLEASE ANSWER ALL QUERIES}

PLEASE NOTE: We cannot accept new source files as corrections for your paper. If possible, please annotate the PDF proof we have sent you with your corrections and upload it via the Author Gateway. Alternatively, you may send us your corrections in list format. You may also upload revised graphics via the Author Gateway.

$\mathrm{AQ}: 1=$ Please provide the issue no. or month, for ref. [3] and [10].

$\mathrm{AQ}: 2$ = Please confirm the author names, article title, journal title, volume no., page range, and year for ref. [15]. Also provide the issue no. and month. 


\title{
Experimental Comparison of the Low-Frequency Noise of Small-Size Magnetic Sensors
}

\author{
Jan Vyhnanek and Pavel Ripka \\ Department of Measurement, Faculty of Electrical Engineering, Czech Technical \\ University in Prague, 16627 Prague, Czech Republic
}

Small-size ac magnetic-field sensors are used for nondestructive testing (NDT), magnetic particle detection, and other applications, which require high spatial resolution. Up to now, inductive coils dominated this area, as their sensitivity at $\mathrm{kHz}$ frequencies, are superior to other magnetic sensors. However, some applications, such as magnetic imaging through conducting sheath, require lower working frequencies, in extreme case units of $\mathrm{Hz}$. We successfully replaced inductive coils by an AMR sensor in NDT application and for distance measurement. In this paper, we compare designs of miniature ac magnetic field sensors, their achievable frequency characteristics, dynamic range, and noise parameters.

Index Terms-Magnetic sensors, noise measurement.

\section{INTRODUCTION}

C OMPARISON of magnetic sensors of different technologies was recently done by Robbes in [1]. He used energy resolution-volume criterion and concluded that SQUID and SERF achieve the best resolution. However, these sensors are not practical for the industrial applications such as nondestructive testing (NDT).

In this paper, we compare commonly available small-size room temperature sensors: an induction coil with $8 \mathrm{~mm}$ long ferrite core (Fig. 1) and commercial fluxgate and AMR sensors. The selected sensors have comparable dimensions of the casing rather than the sensing element size. This is a practical criterion for the design of gradiometers or multiple sensor detectors. Dimensions of the sensing element, however, influence the spatial resolution of the sensor, an important requirement, e.g., in NDT applications, in position sensing, and in the detection of small ferromagnetic or superparamagnetic objects. Gruger [2] describes an array of planar fluxgate sensors for NDT. The sensors are $1 \mathrm{~mm}$ long and they have $0.5 \mathrm{~mm}$ pitch. Vertesy and Gasparics [3] used a similar sensor with time-output and unipolar excitation. Butin et al. [4] and Dolabdjian et al. [5] replaced induction coil in a pulsed eddy current system by GMR sensors. We have used an AMR sensor instead of the induction coil in the eddy-current position and distance sensor [6].

In this paper, we compare sensor noise at low frequencies, i.e., DC to $1 \mathrm{kHz}$ following the study we made on AMR sensors [7]. In this frequency range, the sensor noise is the limiting factor for NDT applications. Similar study of magnetoresistive sensors was made by Stutzke et al. [8].

\section{INDUCTION COIL}

Induction coils are traditionally used in geophysics to measure magnetic field variations [9]. An induction coil can reach

Manuscript received August 10, 2016; revised November 15, 2016; accepted November 19, 2016. Corresponding author: J. Vyhnanek (e-mail: vyhnajan@ fel.cvut.cz).

Color versions of one or more of the figures in this paper are available online at http://ieeexplore.ieee.org.

Digital Object Identifier 10.1109/TMAG.2016.2633398

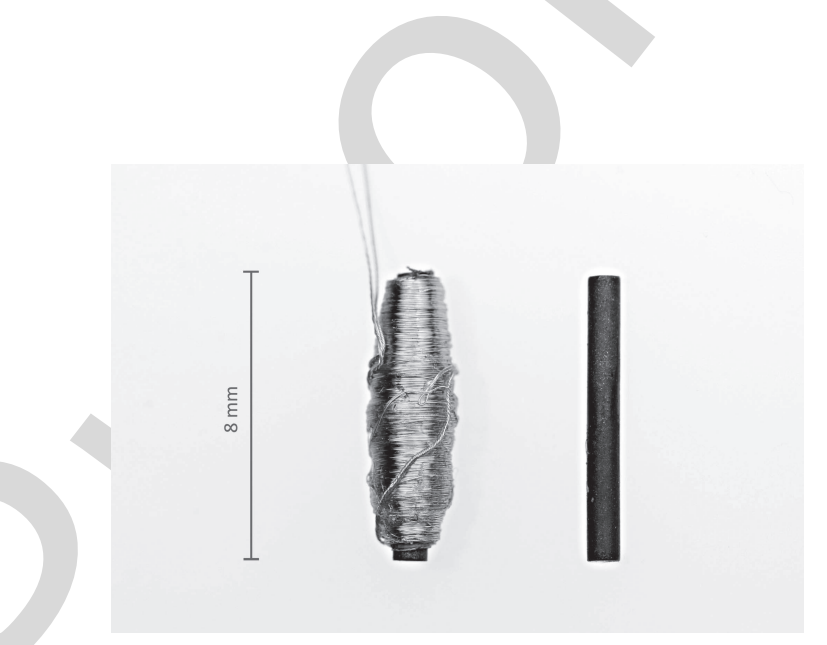

Fig. 1. Sensor with 2000 turns wound around a ferrite core and a ferrite core without the winding.

a resolution of fluxgate sensors at $1 \mathrm{~Hz}$, but the dimensions and weight of such a coil is usually large [10], [11].

In the position detectors with moving magnets, induction sensors have been replaced by Hall and AMR sensors, which have speed-independent signal. However, induction coils are the most popular sensors in eddy current position sensors and NDT systems. Induction coils can be used either in the voltage output mode or in the current output mode. Theoretical model and real data comparison of a coil with the same instrumentation amplifier INA163, which was used here, are given in [12].

An induction coil with 2000 turns and $8 \mathrm{~mm} \times 1 \mathrm{~mm}$ ferrite core was developed in our laboratory and successfully tested in vivo as an inductive distance sensor to monitor gastric motility [13]. The coil is wound with a $0.035 \mathrm{~mm}$ diameter copper wire and its resistance $R_{S}$ is $200 \Omega$.

After inserting the ferrite core, the coil inductance $L_{S}$ was increased by the factor of 13 (from 1.4 to $18.6 \mathrm{mH}$ ) and the sensitivity increased by the factor of 12 at all frequencies. These are lower values than the theoretical apparent permeability of 50 according to [14]. One explanation of this discrepancy may be the influence of the real coil geometry.

The frequency dependence of the sensitivity of voltage output coil is shown in Fig. 2(a). The resonance peak of the 

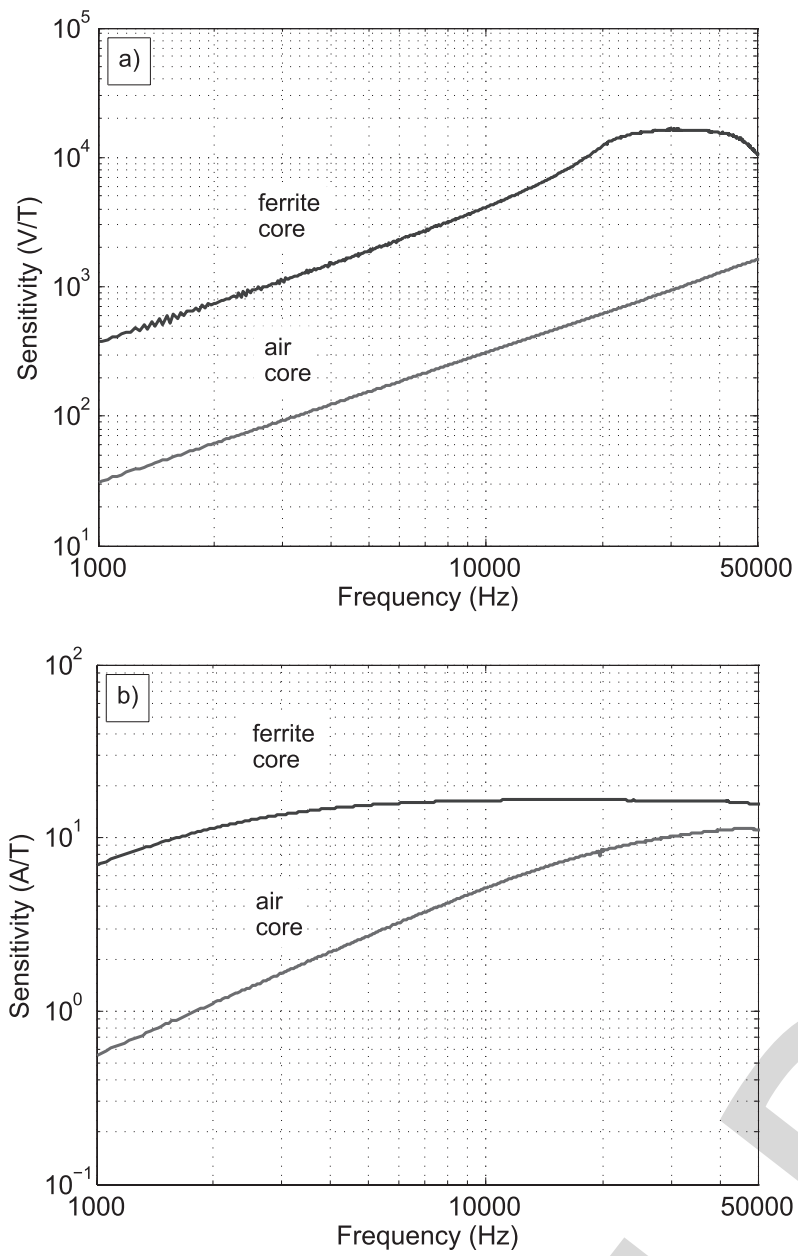

Fig. 2. Frequency dependence of the $8 \mathrm{~mm}$ long induction coil with and without ferrite core (a) with voltage output and (b) with current output.

cored coil is caused by coil self-capacitance in parallel with inductance.

The theoretical disadvantage of the induction coil with voltage output is its strong frequency dependence of sensitivity. The coil with current output is theoretically frequency independent for frequencies higher than

$$
f_{c}=R_{s} /\left(2 \pi L_{s}\right) .
$$

However, for small induction coils, this frequency is very high. The real frequency characteristics of the current output coil with and without a core are shown in Fig. 2(b). For the cored coil and the current output, the measured cutoff frequency corresponds to the theoretical value $f_{c}=1.7 \mathrm{kHz}$ for $L_{s}=$ $18.6 \mathrm{mH}$. For the air coil, the calculated $f_{c}$ is $23 \mathrm{kHz}$.

Fig. 3 compares three conditioning circuits connected to the cored induction coil to select the optimal method of signal processing. Transimpedance amplifiers with INA163 and LT1028 were used for the current output. The value of the conversion resistor is $6 \mathrm{k} \Omega$. The coil in the voltage output mode was connected to a voltage amplifier with INA163 with the gain of 1000 . From the measured characteristics, we may conclude that for this type of the induction coil, voltage amplification is the best to achieve minimum noise.

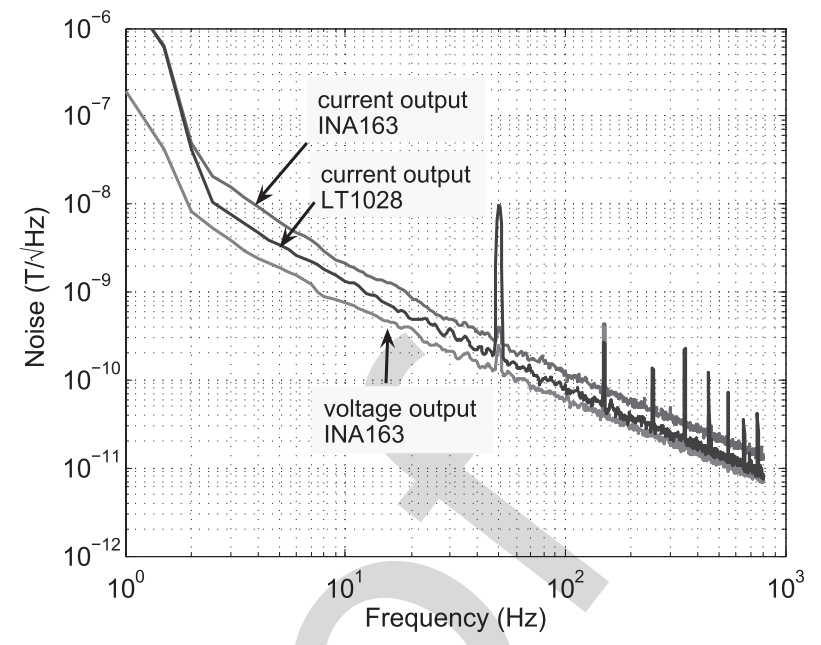

Fig. 3. Comparison of induction coil noise with voltage amplifier and transimpedance amplifier (current output) for $1-800 \mathrm{~Hz}$.
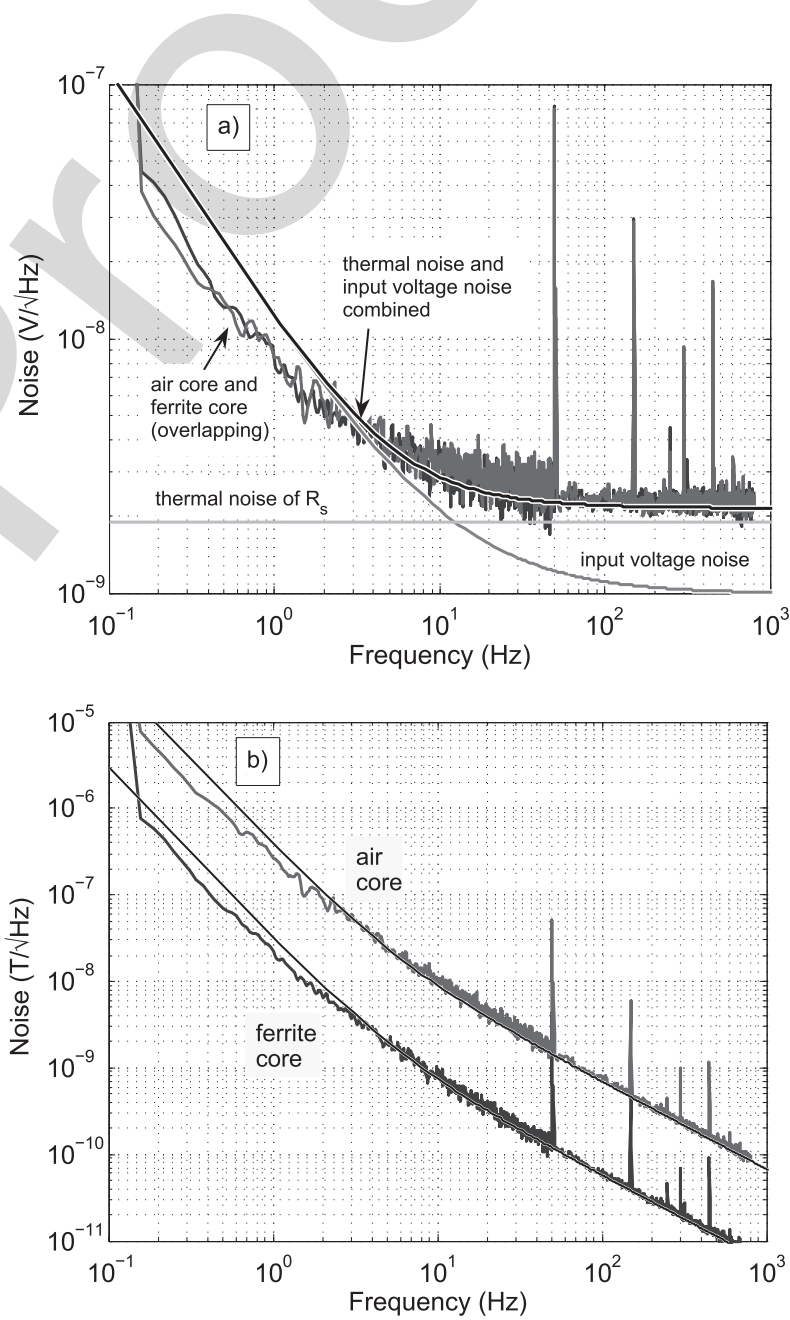

Fig. 4. Induction coil with core connected to INA163 voltage amplifier compared with modeled thermal noise and voltage noise of INA163. (a) In volts. (b) Recalculated in the units of magnetic field.

Fig. 4(a) shows the measured and modeled noise voltage for the voltage output coil compared with the calculated values. For the frequencies below $10 \mathrm{~Hz}$, the dominant source of the noise is $1 / f$ voltage noise of the amplifier, while the 
TABLE I

COMPARISON SUMMARY

\begin{tabular}{|c|c|c|c|c|c|c|c|}
\hline Sensor & Conditioning circuit & $\begin{array}{c}\text { Sensor } \\
\text { dimensions }\left(\mathrm{mm}^{3}\right)\end{array}$ & $\begin{array}{c}\text { Sensor } \\
\text { weight }(\mathrm{g})\end{array}$ & $\begin{array}{l}\text { Freq. upper } \\
\text { limit }(\mathrm{kHz})\end{array}$ & $\begin{array}{c}\text { Sensor } \\
\text { range }(\mathrm{mT})\end{array}$ & $\begin{array}{c}\text { Noise, } 10 \mathrm{~Hz} \\
(\mathrm{nT} / \sqrt{\mathrm{Hz}})\end{array}$ & $\begin{array}{c}\text { Noise, } 100 \mathrm{~Hz} \\
(\mathrm{nT} / \sqrt{ } \mathrm{Hz})\end{array}$ \\
\hline Coil, air core & INA163, $G=1000 \times$ & $8 \times 2.5 \times 2.5$ & 0.01 & $>50$ & $>1000$ & 10 & 0.8 \\
\hline Coil, ferrite c. & INA163, $G=1000 \times$ & $8 \times 2.5 \times 2.5$ & 0.13 & 20 & 5 & 0.8 & 0.07 \\
\hline Coil, fluxgate & Lock-in SR865 & $8 \times 2.5 \times 2.5$ & 0.13 & 1 & $<5$ & 1.2 & 1 \\
\hline HMC1001 & $\mathrm{AD} 8429, \mathrm{G}=100 \times$ & $11 \times 4 \times 2$ & 0.15 & $4^{*}$ & 0.2 & 0.065 & 0.05 \\
\hline HMC2003 & included in sensor & $27 \times 20 \times 9$ & 1.28 & 1 & 0.2 & 0.25 & 0.25 \\
\hline DRV425 & included in sensor & $4 \times 4 \times 0.8$ & 0.04 & 32 & 2 & 1.5 & 1 \\
\hline
\end{tabular}

*4 kHz with $10 \mathrm{kHz}$ flipping and demodulation, $1.2 \mathrm{MHz}$ without flipping

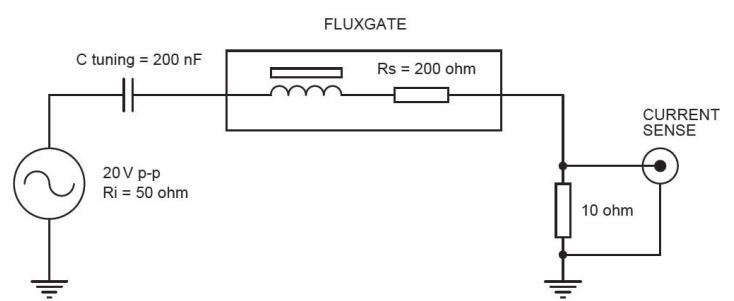

Fig. 5. Setup for the fluxgate sensor with current output.

contribution from the current noise is negligible. The noise model is based on datasheet data. The theoretical white noise of the coil is mainly determined by the thermal noise voltage of the coil resistance and the white noise region $U_{n}$ of the voltage noise of the amplifier; for $R_{s}=200 \Omega, U_{n}=1 \mathrm{nV} / \sqrt{\mathrm{Hz}}$, room temperature $T$, and Boltzmann constant $k$, the combined white noise results in

$$
U_{\text {white_total }}=\sqrt{4 k T R_{S}+U_{n}^{2}}=2.1 \mathrm{nV} / \sqrt{\mathrm{Hz}} .
$$

The measured value is $2.3 \mathrm{nV} / \sqrt{\mathrm{Hz}}$. As the measured voltage noise with and without core is identical, the contribution of the magnetic noise of the core is negligible. Noise recalculated to the field units is shown in Fig. 4(b). It is clear that due to the frequency dependence of the sensitivity, the noise decreases with frequency monotonically. The achieved noise level with the cored coil is $0.8 \mathrm{nT} / \sqrt{\mathrm{Hz}} @ 10 \mathrm{~Hz}$ and $22 \mathrm{nT} / \sqrt{\mathrm{Hz}} @ 1 \mathrm{~Hz}$.

The cored induction coil has a field amplitude range limited by the saturation of the core to $5 \mathrm{mT}$. Compared with that, the upper field range of the air coil is only limited by the output amplifier. In our case, the maximum measurable field on the high-resolution range is $1 \mathrm{mT}$. This field range can be further extended even over $1 \mathrm{~T}$ by decreasing the amplifier gain.

We also tested signal processing by analog integrator: homemade using LT1028 and commercially available Lakeshore 480. Due to the high resistance of the induction coil, the value of feedback capacitor should be about $1 \mu \mathrm{F}$ and resulting sensitivity is very low.

\section{Induction CoIL AS A Single Rod FluXgate}

The described miniature induction coil can be turned into the fluxgate sensor. The advantage of this unusual sensor is that it has only one winding. Setup for the fluxgate mode measurement is shown in Fig. 5. The sensor is excited in the voltage mode using $20 \mathrm{~V}_{\mathrm{p}-\mathrm{p}} / 2.3 \mathrm{kHz}$ sinusoidal voltage. The capacitor $\mathrm{C}$ serves to decouple any dc component in the

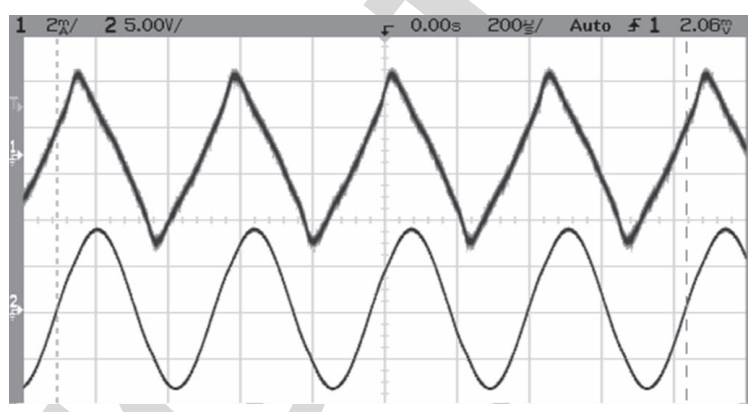

Fig. 6. Sensor current with higher harmonics due to core saturation (upper trace, $2 \mathrm{~mA} / \mathrm{div}$ ) and generator voltage (lower trace, $5 \mathrm{~V} / \mathrm{div}$ ).

excitation and to increase the excitation current amplitude by tuning.

The generator voltage and the corresponding sensor current are shown in Fig. 6. The excitation current was $8 \mathrm{~mA}_{\mathrm{p}-\mathrm{p}}$. When the external dc field is present, second-harmonic component appears in the excitation current. This second harmonics is measured as a voltage drop across the $10 \Omega$ sensing resistor by the SR865 lock-in amplifier. At higher frequencies, most of the noise in the setup comes from the amplifier in this case considering the large feedthrough of the excitation signal to the output current.

Sensitivity dependence on the frequency of the excitation current was measured for constant excitation voltage of $20 \mathrm{~V}_{\mathrm{p}-\mathrm{p}}$ (Fig. 7), and for the noise measurement, an excitation frequency of $2.3 \mathrm{kHz}$ in the high-sensitivity region was selected.

Comparing the noise of fluxgate mode and induction mode (Fig. 8), a crossing of the two characteristics at around $10 \mathrm{~Hz}$ indicates the suitability of each mode for a specified frequency region: for frequencies from DC to $10 \mathrm{~Hz}$, the recommended sensor mode is fluxgate, for higher frequencies induction coil.

\section{Comparison With Commercial Sensors}

We compared the performance of the developed sensors with sensors available on the market. The results are shown in Fig. 9 and a summary of parameters is given in Table I.

HMC2003 is a three-axis magnetic sensor module manufactured by Honeywell, which contains AMR sensor HCM1001 with instrumentation amplifier and a biasing source. The measured noise at $10 \mathrm{~Hz}$ is $250 \mathrm{pT} / \sqrt{\mathrm{Hz}}$. No flipping 


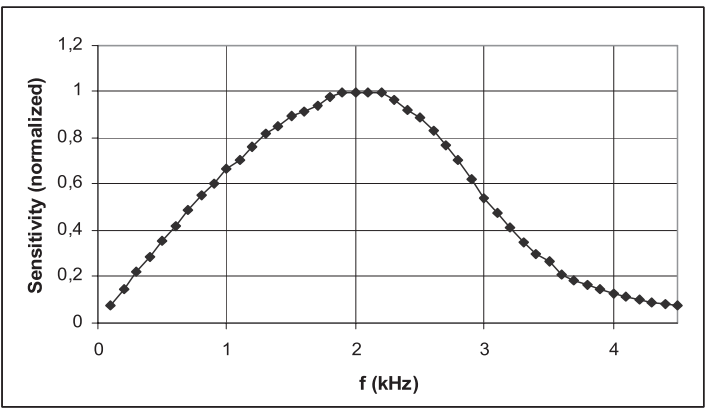

Fig. 7. Sensitivity of the fluxgate sensor in the measurement setup at the variable excitation frequency.

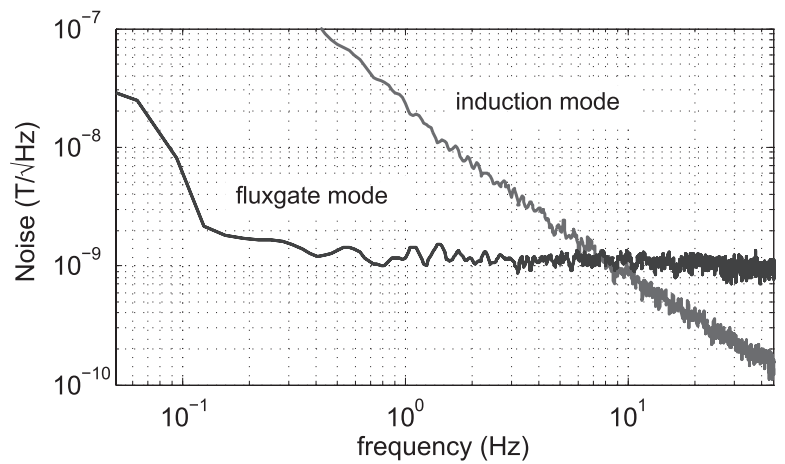

Fig. 8. Coil in fluxgate mode compared with induction mode using voltage output.

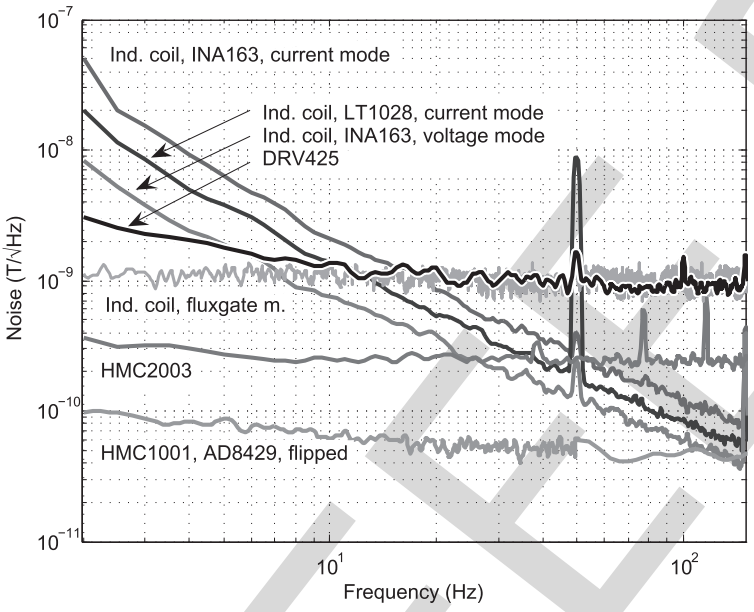

Fig. 9. Comparison of induction coil with AMR and fluxgate sensors for $2-250 \mathrm{~Hz}$.

(set/reset of the magnetic state) was applied. However, for practical applications, the sensor should be periodically remagnetized ("flipped") to ensure zero stability.

The same AMR sensor HMC1001 was characterized with enhanced electronics in [7]. The sensor was flipped at $10 \mathrm{kHz}$ with an amplitude of 3.6 $\mathrm{A}_{\mathrm{p}-\mathrm{p}}$ and connected to a low-noise instrumentation amplifier AD8429 with a gain of 100. The biasing voltage was $5.5 \mathrm{~V}$. After synchronous demodulation, the noise at $10 \mathrm{~Hz}$ is $65 \mathrm{pT} / \sqrt{\mathrm{Hz}}$.

A serious limitation of the AMR sensors is their limited dynamic range. In this case, the maximum measurable field is $0.2 \mathrm{mT}$.

The last sensor in this comparison is integrated fluxgate DRV425 manufactured by Texas Instruments. This device has both microfabricated fluxgate and complete electronics on a single CMOS-chip. We have used it in recommended circuit connection and $5.1 \mathrm{ohm}$ shunt resistor to measure feedback current [15]. The measured noise is $1.5 \mathrm{nT} / \sqrt{\mathrm{Hz}} @ 10 \mathrm{~Hz}$. The maximum field range is $2 \mathrm{mT}$, which is 10 times the range of the AMR sensor.

\section{CONCLUSION}

In this paper, we compared the noise performance of smallsize magnetic sensors suitable for NDT testing. With the exception of DRV425, the tested sensors work in open-loop. We describe small-size induction coil with high field range and noise level of $0.8 \mathrm{nT} / \sqrt{\mathrm{Hz}} @ 10 \mathrm{~Hz}$. At lower frequencies, the fluxgate mode of the same sensor is preferable, which at $1 \mathrm{~Hz}$ achieves already about 20 times better noise. Many industrial applications require high field range. From this point, the integrated fluxgate DRV425 offers the range of $2 \mathrm{mT}$, which is 10 times higher than that of AMR sensors. Our induction sensor works up to $5 \mathrm{mT}$ with core and $>1 \mathrm{~T}$ without the core.

\section{REFERENCES}

[1] D. Robbes, "Highly sensitive magnetometers-A review," Sens. Actuators A, Phys., vol. 129, no. 1, pp. 86-93, 2006.

[2] H. Grüger, "Array of miniaturized fluxgate sensors for non-destructive testing applications," Sens. Actuators A, Phys., vol. 106, no. 1, pp. 326-328, 2003.

[3] G. Vértesy and A. Gasparics, "Nondestructive material evaluation by novel electromagnetic methods," Mater. Sci. Forum, vol. 414, pp. 343-352, 2003.

[4] L. Butin, G. Waché, L. Perez, and C. Dolabdjian, "New NDE perspectives with magnetoresistance array technologies-From research to industrial applications," Insight, Non-Destructive Test. Condition Monitor, vol. 47, no. 5, pp. 280-284, 2005.

[5] C. P. Dolabdjian, L. Perez, V. O. De Haan, and P. A. De Jong, "Performance of magnetic pulsed-eddy-current system using high dynamic and high linearity improved giant magnetoresistance magnetometer," IEEE Sensors J., vol. 6, no. 6, pp. 1511-1517, Jun. 2006.

[6] P. Ripka, J. Vyhnanek, M. Janosek, and J. Vcelak, "AMR proximity sensor with inherent demodulation," IEEE Sensors J., vol. 14, no. 9, pp. 3119-3123, Sep. 2014.

[7] J. Vyhnanek, M. Janosek, and P. Ripka, "Low frequency noise of anisotropic magnetoresistors in DC and AC-excited metal detectors," J. Phys. Conf. Ser, vol. 450, no. 1, p. 012031, 2013.

[8] N. A. Stutzke, S. E. Russek, D. P. Pappas, and M. Tondra, "Low-frequency noise measurements on commercial magnetoresistive magnetic field sensors," J. Appl. Phys., vol. 97, no. 10 pp. 10Q107-1-10Q107-3, 2005.

[9] S. Tumanski, "Induction coil sensors-A review," Meas. Sci. Technol., vol. 18, no. 3, pp. R31-R46, 2007.

[10] A. Roux et al., "The search coil magnetometer for THEMIS," Space Sci. Rev., vol. 141, pp. 265-275, 2008.

[11] E. Paperno and A. Grosz, "A miniature and ultralow power search coi optimized for a $20 \mathrm{mHz}$ to $2 \mathrm{kHz}$ frequency range," J. Appl. Phys., vol. 105, no. 7, p. 07E708, 2009.

[12] M. Timofeeva, G. Allegre, D. Robbes, and S. Flament, "Differentia search coils based magnetometers: Conditioning, magnetic sensitivity, spatial resolution," Sensors Transducers J., vol. 14, no. 1, pp. 134-150, 2012.

[13] J. Tomek, "Inductive contactless distance measurement intended for a gastric electrical implant," Acta Polytech., vol. 47, nos. 4-5, pp. 76-79, 2007.

[14] P. Ripka, "Induction sensors," in Magnetic Sensors and Magnetometers, P. Ripka ed. Norwood, MA, USA: Artech House, 2001.

[15] M. F. Snoeij, V. Schaffer, S. Udayashankar, and V. M. Ivanov, "An integrated fluxgate magnetometer for use in closed-loop/open-loop isolated current sensing," IEEE J. Solid-State Circuits, vol. 51, pp. 1684-1694, 2016. 


\section{AUTHOR QUERIES}

\section{AUTHOR PLEASE ANSWER ALL QUERIES}

PLEASE NOTE: We cannot accept new source files as corrections for your paper. If possible, please annotate the PDF proof we have sent you with your corrections and upload it via the Author Gateway. Alternatively, you may send us your corrections in list format. You may also upload revised graphics via the Author Gateway.

AQ:1 = Please provide the issue no. or month, for ref. [3] and [10].

$\mathrm{AQ}: 2$ = Please confirm the author names, article title, journal title, volume no., page range, and year for ref. [15]. Also provide the issue no. and month. 